\title{
Tired and Apprehensive: Anxiety Amplifies the Impact of Sleep Loss on Aversive Brain Anticipation
}

\author{
Andrea N. Goldstein, ${ }^{1}$ Stephanie M. Greer, ${ }^{1}$ Jared M. Saletin, ${ }^{2}$ Allison G. Harvey, ${ }^{2}$ Jack B. Nitschke, ${ }^{3}$ \\ and Matthew P. Walker ${ }^{1,2}$ \\ ${ }^{1}$ Helen Wills Neuroscience Institute, University of California, Berkeley, California 94720-1650, ${ }^{2}$ Department of Psychology, University of California, \\ Berkeley, California 94720-1650, and ${ }^{3}$ Waisman Laboratory for Brain Imaging and Behavior, Departments of Psychology and Psychiatry, University of \\ Wisconsin-Madison, Madison, Wisconsin 53705-2280
}

Anticipation is an adaptive process, aiding preparatory responses to potentially threatening events. However, excessive anticipatory responding and associated hyper-reactivity in the amygdala and insula are integral to anxiety disorders. Despite the co-occurrence of sleep disruption and anxiety disorders, the impact of sleep loss on affective anticipatory brain mechanisms, and the interaction with anxiety, remains unknown. Here, we demonstrate that sleep loss amplifies preemptive responding in the amygdala and anterior insula during affective anticipation in humans, especially for cues with high predictive certainty. Furthermore, trait anxiety significantly determined the degree of such neural vulnerability to sleep loss: individuals with highest trait anxiety showed the greatest increase in anticipatory insula activity when sleep deprived. Together, these data support a neuropathological model in which sleep disruption may contribute to the maintenance and/or exacerbation of anxiety through its impact on anticipatory brain function. They further raise the therapeutic possibility that targeted sleep restoration in anxiety may ameliorate excessive anticipatory responding and associated clinical symptomatology.

\section{Introduction}

Anticipation is an adaptive process, mobilizing preparatory responses to impending threat or danger (McNally and Westbrook, 2006). However, in excess, anticipation can be maladaptive, contributing to rumination, worry, and the debilitating social dysfunction associated with anxiety disorders (Etkin and Wager, 2007; Nitschke et al., 2009). Anatomically, lesion and neuroimaging reports in humans have characterized a brain network that supports affective anticipation, including the amygdala and anterior insula cortex (Masaoka et al., 2003; Simmons et al., 2004, 2006; Nitschke et al., 2006; Kesner and Gilbert, 2007; Sarinopoulos et al., 2010; Grupe et al., 2012). The latter also responds preferentially to anticipation uncertainty when the impending outcome is unclear (Dunsmoor et al., 2007; Herwig et al., 2007; Somerville et al., 2013). Moreover, hyperactivity within these same two regions has consistently been implicated in the psychopathology of anxiety disorders (Etkin and Wager, 2007).

Received Dec. 3, 2012; revised April 26, 2013; accepted April 28, 2013.

Author contributions: A.N.G., J.B.N., and M.P.W. designed research;A.N.G. and S.M.G. performed research; J.M.S. contributed unpublished reagents/analytic tools; A.N.G. analyzed data; A.N.G., A.G.H., J.B.N., and M.P.W. wrote the paper.

This work was supported by Awards R01-MH093537 (M.P.W.), R21-DA031939 (M.P.W.), and F31-MH094075 (A.N.G.) from the National Institutes of Health. We thank Matthew Brett for helpful advice on fMRI analyses and the following research assistants involved in the study: Kelsey Hudson, Linda Nix, Graham Cooper, Aubrianna Zhu, Jamie Sallee, Sarah Roth, Jeff Wayland, Alex Beagle, Mana Kahali, Anna Akullian, Brian Johnson, and Roupen Khanjian. The authors declare no competing financial interests.

Correspondence should be addressed to Matthew P. Walker, Department of Psychology, University of California, Berkeley, CA 94720-1650. E-mail: mpwalker@berkeley.edu.

DOI:10.1523/JNEUROSCI.5578-12.2013

Copyright $\odot 2013$ the authors $\quad 0270-6474 / 13 / 3310607-09 \$ 15.00 / 0$
Independent of anticipation, emerging literature indicates a role for sleep in affective brain regulation. For example, sleep loss amplifies limbic reactivity in response to aversive stimuli (Yoo et al., 2007). Conversely, a night of sleep palliatively resets limbic responsivity to emotional events (van der Helm et al., 2011). Moreover, patients with anxiety disorders commonly experience co-occurring sleep abnormalities (Harvey et al., 2011), further suggesting an association between sleep, anxiety, and affective brain function.

Building on this evidence, the current study directly tested the impact of sleep deprivation on anticipatory brain responses preceding emotionally salient events. We hypothesized that sleep deprivation would increase anticipatory signaling within the amygdala and anterior insula. The valence and certainty of the anticipatory cues were independently manipulated to test the prediction that the anticipatory amygdala activity would be particularly sensitive to cue valence (Yoo et al., 2007), whereas the anterior insula would show sensitivity to cue certainty (Dunsmoor et al., 2007). Finally, we sought to determine whether trait anxiety conferred vulnerability to the detrimental effects of sleep deprivation on anticipatory brain function, with higher levels of trait anxiety predicting greater susceptibility to amplified amygdala and insula anticipatory responding following sleep loss.

\section{Materials and Methods}

Participants. Eighteen healthy adults, age $18-30$ years (mean: 19.6; SD \pm 1.45 years; 9 female; Table 1) completed a repeated-measures cross-over design (described below). Participants abstained from caffeine and alcohol for the $72 \mathrm{~h}$ before and during the entire course of the study and kept a normal sleep-wake rhythm (7-9 h of sleep per night with sleep onset 
Table 1. Demographics and trait and state questionnaire data (mean \pm SD)

\begin{tabular}{lcc}
\hline Demographic information & 18 & \\
$n$ & $19.6 \pm 1.45$ & \\
Age & 9 male, 9 female & \\
Gender & $32.33 \pm 9.29$ & \\
Trait measures & $1.18 \pm 3.63$ & \\
Anxiety (STAl trait) & $35.72 \pm 5.70$ & \\
Depression (QIDS) & $59.56 \pm 15.50$ & Sleep deprived \\
NEO (neuroticism) & Sleep rested & \\
IUS & $3.46 \pm 0.22$ \\
State measures & $1.82 \pm 0.82$ & $4.35 \pm 1.32$ \\
Subjective sleepiness & & \\
$\quad$ Evening & $28.11 \pm 7.18$ & $28.34 \pm 7.70$ \\
$\quad$ Morning & $30.29 \pm 7.50$ & $39.47 \pm 10.20$ \\
Anxiety (STAl-state) & & \\
$\quad$ Evening & &
\end{tabular}

before 1:00 A.M. and rise time no later than 9:00 A.M.) for the 3 nights before the study participation, as verified by sleep logs and actigraphy (a wristwatch movement sensor, sensitive to wake and sleep states). Exclusion criteria, assessed using a prescreening semistructured interview, were as follows: a history of sleep disorders, neurologic disorders, open and closed head injury, Axis I psychiatric disorders according to the DSM-IV-TR (Diagnostic and Statistical Manual of Mental Disorders, fourth edition, text revision) criteria (encompassing mental disorders including depression, anxiety disorders, bipolar disorder, attention deficit disorder, and schizophrenia), history of drug abuse, and current use of antidepressant, psychostimulant, or hypnotic medication. Subjects who reported drinking $\geq 3$ caffeine-containing beverages a day, such as caffeinated coffee, tea, or soft drinks, were excluded. The study was approved by the local human ethics studies committee, with all participants providing written informed consent.

Experimental design. Following screening, participants entered the repeated-measures study design (Fig. $1 \mathrm{~A}$ ), performing the emotionalanticipation task twice inside the MRI scanner: once after a night of sleep and once after $24 \mathrm{~h}$ of total sleep deprivation. In the sleep-deprived session, participants arrived at the laboratory at 9:00 P.M. and were continuously monitored throughout the enforced waking period by trained personnel, independently confirmed using actigraphy monitoring. Participants were typically run as a dyad, and were allowed a degree of social interaction with the experimenters and each other across the deprivation night before the first behavioral task. This choice was, in part, to allow a degree of ecological similarity to real-world circumstances, as societal sleep deprivation commonly occurs in a nonisolated context. Activities during the sleep deprivation period were limited to using the internet, writing and reading e-mails, taking short walks, reading, watching movies of low emotionality, and playing board games, thereby providing a standardized regimen of waking activity without undue stress. The following morning, at $\sim 8: 30$ A.M. ( $\pm 90 \mathrm{~min}$ ), the participants were separated and performed the emotional-anticipation task in the MRI scanner.

In the sleep-rested session, participants came to the laboratory at 8:00 P.M. and were prepared for an $\sim 8 \mathrm{~h}$ in bed polysomnographic (PSG) night of sleep recording in the laboratory (11:00 P.M. to 7:30 A.M. \pm 30 min; details below). Similar to the deprived condition, participants performed an alternate version of the emotional-anticipation task in the MRI scanner at $\sim 9: 00$ A.M. ( $\pm 90 \mathrm{~min}$ ). Test sessions were separated by at least $6 \mathrm{~d}$ (mean 12.42), with the order of the sleep-rested and sleepdeprived sessions counterbalanced across subjects.

Trait anxiety and sleep history measures. Trait anxiety was determined using the State-Trait Anxiety Inventory (STAI) (Spielbeger, 1983), administered on the first experimental visit. The STAI assesses negative affect symptoms of relevance to both anxiety and mood pathology (Watson et al., 1995; Nitschke et al., 2001). To determine the specificity of relationship between changes in brain reactivity and trait anxiety, other trait personality factors commonly examined in the context of anxiety were measured. These included the neuroticism scale from the NEO personality inventory (Costa and McCrae, 1997), the Intolerance of Uncertainty Scale (IUS) (Freeston et al., 1994), and the Quick Inventory of Depressive Symptomatology (QIDS) (Rush et al., 2003).

To assess the degree of difference between the structured sleep schedule of the experiment and each participant's unrestricted sleep schedule, participants completed the Pittsburgh Sleep Quality Index upon study entry. This instrument contains questions relating to the bed time, rise time, and duration of sleep episodes across the past month (Buysse et al., 1989). Additionally, to better characterize recent sleep status, participants further completed sleep logs $5 \mathrm{~d}$ before each experimental session. Participants conformed to the structured sleep schedule during the month before the experiment, including across the $5 \mathrm{~d}$ before the experimental session. Specifically, in the month leading up to the study, participants reported average bed times before 1:00 A.M. (mean: 12:13 A.M.; $\mathrm{SD} \pm 50 \mathrm{~min}$ ), rise times before 9:00 A.M. (mean: 8:00 A.M.; $\mathrm{SD} \pm 62$ $\mathrm{min}$ ) and sleep duration lengths between 7 and $9 \mathrm{~h}$ (mean: $7.53 \mathrm{~h}$; $\mathrm{SD} \pm$ $0.76 \mathrm{~h}$ ). Similarly, for the $2 \mathrm{~d}$ before the start of the structured sleep schedule, participants reported sleep-log mean bed times of 12:21 A.M. ( $\mathrm{SD} \pm 45 \mathrm{~min}$ ), mean rise times of 7:53 A.M. ( $\mathrm{SD} \pm 42 \mathrm{~min}$ ) and mean sleep durations of $7.53 \mathrm{~h}(\mathrm{SD} \pm 0.52 \mathrm{~h})$. While it is important to note the inherent limitations of self-report measures, these findings support the likelihood that participants were entering the study in a rested state, and that their normative schedules were congruent with the study requirements. Sleep statistics for the night of PSG recorded sleep in the sleeprested session are provided in Table 2 , and conform to population norms for this age range (Ohayon et al., 2004).

Subjective anxiety and sleepiness changes. To assess more transient state anxiety levels beyond trait, we administered the state version of the STAI questionnaire (Spielbeger, 1983) on the evening of both experimental visits and the following morning before each MRI scan. Similarly, to assess changes of subjective alertness, participants completed the validated Stanford Sleepiness Scale (SSS) (Hoddes et al., 1973). This standard measure of subjective alertness ranges across a seven-point scale, with " 1 " being most alert, and was administered on the evening of both experimental visits and the following morning, before each fMRI emotional-anticipation task session.

fMRI emotional-anticipation task. Each subject was administered two versions of a validated fMRI emotional-anticipation task (Mackiewicz et al., 2006; Nitschke et al., 2006, 2009; Sarinopoulos et al., 2010), which were counterbalanced across sleep-rested and sleep-deprived fMRI sessions. For both versions, the task contained three different trial types: negative, neutral, and ambiguous (Fig. $1 \mathrm{~B}$ ). Each trial type consisted of an anticipatory cue, followed by the presentation of an emotionally negative or neutral picture stimulus, the structure and timing of which is outlined in Figure 1C. In addition, null trial events were pseudorandomly interspersed between these anticipation trials, during which a fixation point was displayed on the screen for a jittered duration (maximum, $5 \mathrm{~s}$; minimum, $1.5 \mathrm{~s}$; mean, $2.5 \mathrm{~s}$ ), advantageously producing intertrial interval variability optimal for event-related fMRI design (Dale, 1999). The inclusion of the three distinct anticipation trial types offered the ability to discriminate between the following possible sleep deprivation outcomes: (1) a generalized change in anticipatory signaling, regardless of cue type; (2) a valence-sensitive change in anticipatory signaling, dependent on aversive outcome [e.g., negative cue (100\% aversive) $>$ ambiguous cue (50\% aversive) $>$ neutral cue $(0 \%$ aversive $)]$; or (3) an outcomecertainty sensitive change in anticipatory signaling related to whether the cues accurately predicted the outcome with certainty (negative cue and neutral cue) or uncertainty (ambiguous cue). As in previous studies (Mackiewicz et al., 2006; Nitschke et al., 2006, 2009; Sarinopoulos et al., 2010), subjects were instructed about all cue-picture pairings before scanning, but were not informed of the proportion of aversive versus neutral pictures that followed the ambiguous cue. Both task versions had 90 trials consisting of 30 negative, 30 neutral, and 30 ambiguous trials, with the latter further divided into 15 ambiguous-negative and 15 ambiguous-neutral trials ( 60 null events were also included). Each of three functional runs consisted of 30 trials and 20 null events.

For each of the two task versions, unique negative and neutral images were selected from a standardized affective picture set (Lang et al., 1997) defined on valence and arousal parameters. The negative stimulus sets 
A

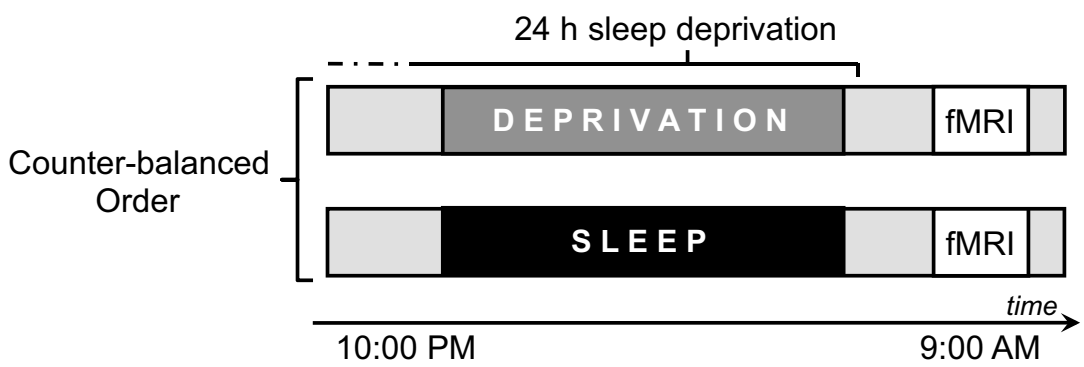

B

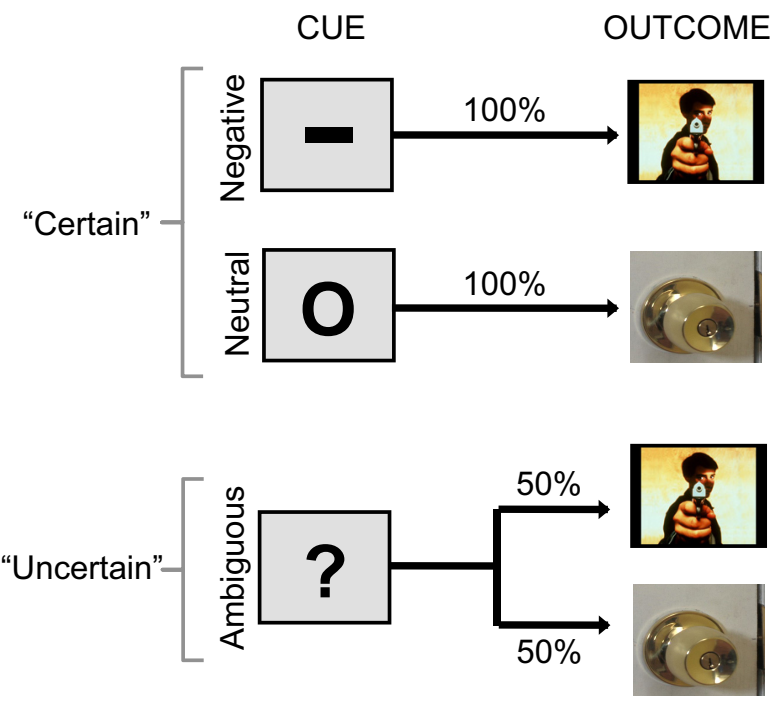

C

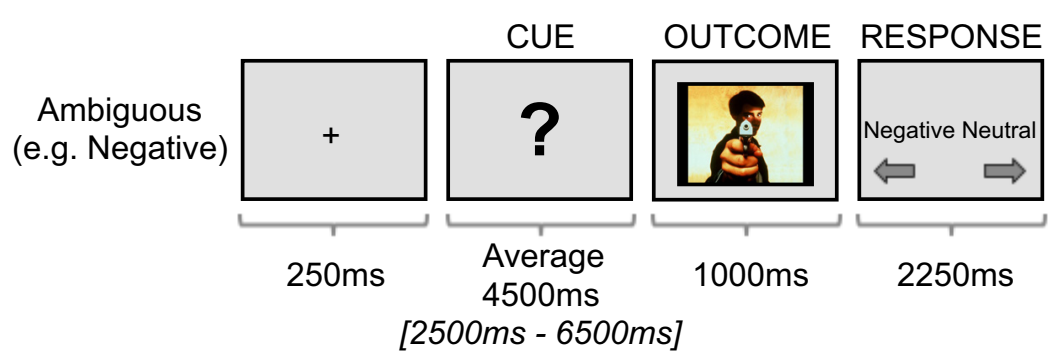

Figure 1. Study design. $\boldsymbol{A}$, Time course of experiment for both the sleep-deprived and sleep-rested conditions. $\boldsymbol{B}$, fMRI anticipation reactivity task trial types. Each trial consisted of an anticipatory cue followed by either an emotional negative or neutral picture stimulus. For negative trials, the anticipation cue was a red " - " symbol that was always followed by a negative picture. For the neutral trials, the anticipation cue was a yellow " 0 " symbol that was al ways followed by a neutral picture. For ambiguous trials, the anticipation cue was a white "?" symbol, which was followed by either a negative or a neutral picture at exactly a 50:50 ratio. C, An example anticipation reactivity task trial with timing. Each anticipation trial lasted an average of $8.75 \mathrm{~s}$. Following a fixation screen, the trial proceeded with (1) the cued anticipation phase, in which one of the three warning cues were presented using a variable jittered time duration for optimal signal estimation (maximum, $5.6 \mathrm{~s}$; minimum, $2.5 \mathrm{~s}$; mean, $4.5 \mathrm{~s}$ ) (Dale, 1999); (2) the stimulus reactivity phase, in which the emotionally negative or neutral image was presented (1 s); and (3) the response period, where subjects made a categorical emotionality judgment using a button-press rating (negative/neutral; $2.5 \mathrm{~s}$ ), also confirming wakefulness. Pseudorandomly interspersed between these anticipation trials were null trial events (data not shown), where a fixation point was displayed on the screen for a jittered duration (maximum, $5 \mathrm{~s}$; minimum, $1.5 \mathrm{~s}$; mean, $2.5 \mathrm{~s}$ ), serving as both a baseline condition as well as modulating intertrial interval variability for optimal modeling of trial events.

contained images with low valance and high arousal (Set 1 valence: range, 1.40-2.99; mean $\pm \mathrm{SD}, 2.10 \pm 0.40$; Set 2 valence: range, 1.48-3.10; mean $\pm \mathrm{SD}, 2.10 \pm 0.40$; Set 1 arousal: range, 5.62-7.35; mean $\pm \mathrm{SD}$, $6.40 \pm 0.42$; Set 2 arousal: range, 5.5-7.29; mean \pm SD, $6.34 \pm 0.47)$. No set was statistically different from any other set in terms of valance $(p>$ $0.97)$ or arousal $(p>0.50)$. Similarly, both task versions of the neutral stimulus set contained images with middle valence and low arousal (Set 1 valence: range, 4.39-5.61; mean $\pm \mathrm{SD}, 5.01 \pm 0.28$; Set 2 valence: range,
4.23-5.64; mean \pm SD, $4.99 \pm 0.32$; Set 1 arousal: range, 1.72-3.64; mean $\pm \mathrm{SD}, 2.96 \pm 0.40$; Set 2 arousal: range, $1.76-3.63$; mean $\pm \mathrm{SD}, 2.92 \pm$ $0.45)$, none of which differed on the basis of valence $(p>0.70)$ or arousal $(p>0.65)$. Across the two task versions, the negative set had lower valence ratings $(p<0.001)$ and higher arousal ratings than the neutral set $(p<0.001)$.

$f M R I$ acquisition. Blood oxygenation leveldependent contrast functional images were acquired with echo-planar T2*-weighted imaging using a Siemens 3 tesla MRI scanner with a 12-channel head coil. Each image volume consisted of 32 ascending $3.5 \mathrm{~mm}$ slices ( $96 \times$ 96 matrix; TR, $2000 \mathrm{~ms}$; TE, $28 \mathrm{~ms}$; size, $2.5 \times$ $2.5 \times 3.5 \mathrm{~mm}$; FOV, $224 \mathrm{~mm}$; flip angle, $\left.90^{\circ}\right)$. A high-resolution T1-weighted structural scan was acquired at the end of the sleep-rested session $(256 \times 256$ matrix; TR, 1900; TE, 2.52; flip angle, $9^{\circ}$; FOV , $256 \mathrm{~mm}$; size, $1 \times 1 \times 1 \mathrm{~mm}$ ). Concurrent eye tracking was used to further verify wakefulness during both test sessions (ViewPoint Eye Tracker; Arrington Research).

fMRI analysis. Preprocessing and data analysis were performed using Statistical Parametric Mapping software implemented in Matlab (SPM8; Wellcome Department of Cognitive Neurology). Images were motion corrected and slice scan time corrected, and then spatially normalized to the Montreal Neurological Institute (MNI) template and smoothed using an $8 \mathrm{~mm}$ full-width-at-half-maximum Gaussian kernel using default parameters in SPM8. For each subject, trial-related activity was assessed by convolving a vector of trial onsets with a canonical hemodynamic response function. The six movement-related covariates ( 3 rigidbody translations and 3 rotations determined from the realignment preprocessing step) were used as regressors in the design matrix for modeling movement-related artifact in the time series. Additionally, a white-matter regressor was included to control for physiological noise. Nonsphericity of the error covariance was accommodated for using a first-order autoregressive model, in which the temporal autocorrelation was estimated by pooling over suprathresholds (Friston et al., 2002).

A general linear model (Friston et al., 1994), specified for each participant to investigate the effects of interest, focused on the anticipation period to test our specific hypotheses. Contrasts were created at the first (individual) level with four events: negative cues, neutral cues, ambiguous cues, and null events. The experimental hypotheses were tested at the second (group) level using a validated voxelwise smallvolume correction approach (Poldrack, 2007; Poldrack and Mumford, 2009) focusing on amygdala and anterior insula regions of interest (ROIs). This voxelwise method reports activation differences only from significant voxels within each ROI using a familywise error (FWE) correction, thresholded at $p<0.05$. ROI volumes were defined as $6 \mathrm{~mm}$ spheres centered on a set of peak activations observed in previously published neuroimaging studies investigating anxiety-related abnormalities in emotional anticipation [MNI coordinates $(x, y, z)$ : left amygdala, -17 , $-8,-14$; right amygdala, 22, $-5,-13$; (Nitschke et al., 2009); left anterior insula, $-29,24,11$; right anterior insula, 33, 17, 15; (Sarinopoulos et 
Table 2. Polysomnography sleep-stage values for the sleep-rested night (mean \pm SD)

\begin{tabular}{lrc}
\hline & \multicolumn{1}{c}{ Time $(\mathrm{min})$} & Percentage of total sleep time \\
\hline Time in bed & $511.92 \pm 30.7$ & \\
Sleep latency & $14.22 \pm 16.8$ & \\
Total sleep time & $469.43 \pm 38.7$ & \\
WASO $_{\text {NREM stage 1 }}^{a}$ & $23.39 \pm 22.6$ & \\
NREM stage 2 $^{a}$ & $25.72 \pm 10.4$ & $5.53 \pm 2.4$ \\
NREM SWS $^{a}$ & $253.15 \pm 34.1$ & $53.87 \pm 5.2$ \\
REM $^{a}$ & $90.35 \pm 28.4$ & $19.41 \pm 6.7$ \\
\hline
\end{tabular}

WASO, wake after sleep onset; NREM, nonrapid-eye-movement sleep; SWS, slow-wave sleep (SWS, NREM stage 3 and 4); REM, rapid-eye-movement sleep. Sleep efficiency (total sleep time divided by time in bed) was within normal levels $(91.7 \pm 5.1 \%)$.

${ }^{a}$ Obtained by $100 \%$ of participants.

al., 2010)]. Differences were examined using a repeated-measures condition (sleep-rested, sleep-deprived)-cue type (negative, neutral, ambiguous) ANOVA, implemented in SPM8. Effects outside our a priori ROIs are reported for descriptive purposes only, using whole-brain voxelwise ANOVA analyses, thresholded at $p<0.001$ (uncorrected).

To further assess hypothesized effects in the amygdala and anterior insula, we supplemented the voxelwise analyses with an ROI-based approach, averaging activity across the entire ROI (Poldrack, 2007; Kriegeskorte et al., 2009; Poldrack and Mumford, 2009; Vul et al., 2009). For this method, average parameter estimates were extracted from the entire 6 $\mathrm{mm}$ amygdala and anterior insula ROI volumes independently, and then entered into a condition (sleep-rested, sleep-deprived)-cue type (negative, neutral, ambiguous) repeated-measures ANOVA, performed using STATA 11 (StataCorp). Main effects and interactions were tested using a significance of $p<0.05$.

To test the hypothesis that neural changes in anticipatory reactivity following sleep loss were associated with innate anxiety, we regressed trait STAI anxiety scores against the sleep-deprivation difference in anticipatory reactivity in amygdala and insula ROIs, again using a voxelwise approach corrected at a threshold of $p<0.05$ FWE. We then further examined this same relationship using the alternate average ROI approach, correlating individual STAI trait scores with the average parameter estimates extracted from the entire ROIs for all cues using a significance threshold of $p<0.05$ (performed in STATA 11; (Poldrack, 2007; Poldrack and Mumford, 2009; Vul et al., 2009). Trait anxiety effects beyond our a priori ROIs are reported using whole-brain voxelwise regression analysis, thresholded at $p<0.001$ (uncorrected). Finally, to determine the specificity of associations with trait anxiety, we repeated this regression approach on an exploratory basis with other trait questionnaire measures (QIDS, NEO Neuroticism, IUS), as well as state questionnaire measures (STAI state, SSS).

\section{Results}

Impact of sleep deprivation on anticipatory brain function

First, we sought to determine the impact of sleep deprivation on anticipatory responding within the amygdala and anterior insula, examined using a voxelwise condition (sleep-rested, sleep-deprived)-cue type (negative, neutral, ambiguous) repeated-measures ANOVA. A main effect of condition was observed in the bilateral amygdala (Fig. $2 A ; p<0.05$ FWE corrected), with sleep deprivation amplifying anticipatory activity, regardless of cue type. Replicating these voxelwise results, the complementary ROI-based analyses examining average activity from the entire amygdala ROI confirmed the main effect of condition (left: $F=10.12, p=0.006$; right: $F=10.91, p=0.004$ ), and similarly confirmed the lack of a significant cue type interaction (left: $F=1.31, p=0.20$; right: $F=0.18, p=0.84$ ).

For the right anterior insula, the voxelwise ANOVA revealed a main effect of condition and a condition-cue type interaction (Fig. 2B; $p<0.05$ FWE corrected; with no significant effects identified for the left anterior insula). These right anterior insula findings were confirmed by ROI-based analyses for activity averaged across the entire ROI (condition: $F=13.19, p=0.002$; condition-cue type: $F=4.15, p=0.02$ ). For both of these approaches, the condition-cue type interaction was driven by cue uncertainty rather than cue valence. Specifically, post hoc analyses exploring the interaction revealed that in the sleep-rested condition (Fig. $2 B$ ), the right anterior insula demonstrated a typical profile of preferential sensitivity to anticipation uncertainty (Dunsmoor et al., 2007; Herwig et al., 2007; Somerville et al., 2013), with stronger responding to the ambiguous cue relative to the neutral cue $(T=2.45, p=0.03)$, and marginally so relative to the negative cue $(T=1.67, p=0.11)$. However, this profile of insula signaling was disrupted by sleep deprivation, with significantly stronger anticipatory responding to the negative cue compared with the ambiguous cue $(T=2.33, p=0.03)$, and no difference in reactivity to the ambiguous cue compared with the neutral cue $(T=0.50, p=0.49)$. When comparing the two conditions, sleep deprivation showed larger right anterior insula responses for both cues signaling certainty relative to the sleeprested condition, regardless of valence (negative: $T=4.13, p=$ 0.001, neutral: $T=2.65, p=0.02$ ), with no difference observed for the ambiguous cue $(T=1.00, p=0.33)$. This right anterior insula finding was not asymmetric, as indicated by an analogous ANOVA that included hemisphere (left, right) as an additional factor. There were no main or interaction effects with hemisphere for the a priori left insula ROI (all $p>0.10$; similar null findings were observed for a left insula region derived by flipping the sign of the $x$-coordinate for the a priori right insula ROI, thus resulting in the homologous location). The above amygdala and anterior insula effects were also observed in an exploratory whole-brain voxelwise analysis at $p<0.001$ (uncorrected, Tables 3, 4).

Although the order of the sleep-rested and sleep-deprived sessions were counterbalanced across subjects, we conducted cautionary analogous ANOVAs, but with order included as a factor. Results were unchanged for the amygdala main effect of condition (left: $F=10.20, p=0.006$; right: $F=10.93, p=0.0045)$ and for the right anterior insula main effect of condition $(F=$ $12.79, p=0.003)$ and condition-cue type interaction $(F=$ 4.8, $p=0.02$ ).

In sum, these results demonstrate that sleep loss triggered a generalized anticipatory response within the amygdala, independent of certainty as well as valence. Furthermore, sleep deprivation not only amplified activity in the anterior insula, but disrupted this preemptive signaling, inverting the common profile of uncertainty responsivity observed in the sleep-rested condition to one that no longer faithfully signaled uncertainty.

\section{Sleep deprivation, trait anxiety, and anticipatory brain function}

Testing our third hypothesis, we examined whether trait levels of anxiety within a given individual conferred increasing neural susceptibility to the impact of sleep deprivation. Voxelwise regression analyses using the right anterior insula ROI as a mask indicated that STAI trait anxiety scores positively correlated with the increased anticipatory signaling within the right anterior insula following deprivation, relative to the rested condition (Fig. $3 A$ ). That is, individuals with highest STAI trait anxiety levels demonstrated the greatest vulnerability to the amplifying anticipatory effects of sleep deprivation, reflected by the largest increase in anterior insula reactivity across all cues. This finding was confirmed by ROI-based regression analyses $(r=0.55, p=0.02$; Fig. 3B) (Poldrack, 2007; Kriegeskorte et al., 2009; Poldrack and Mumford, 2009; Vul et al., 2009), and also evident as a peak in the 
A
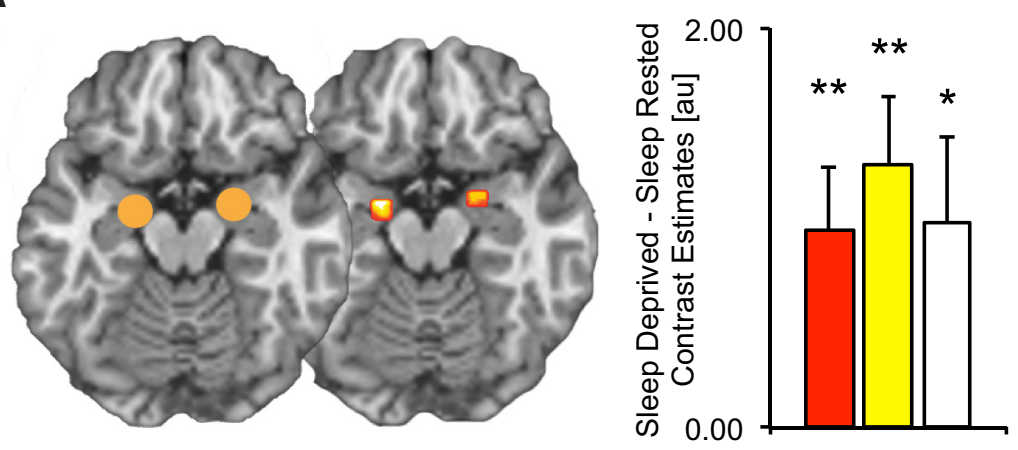

Aversive
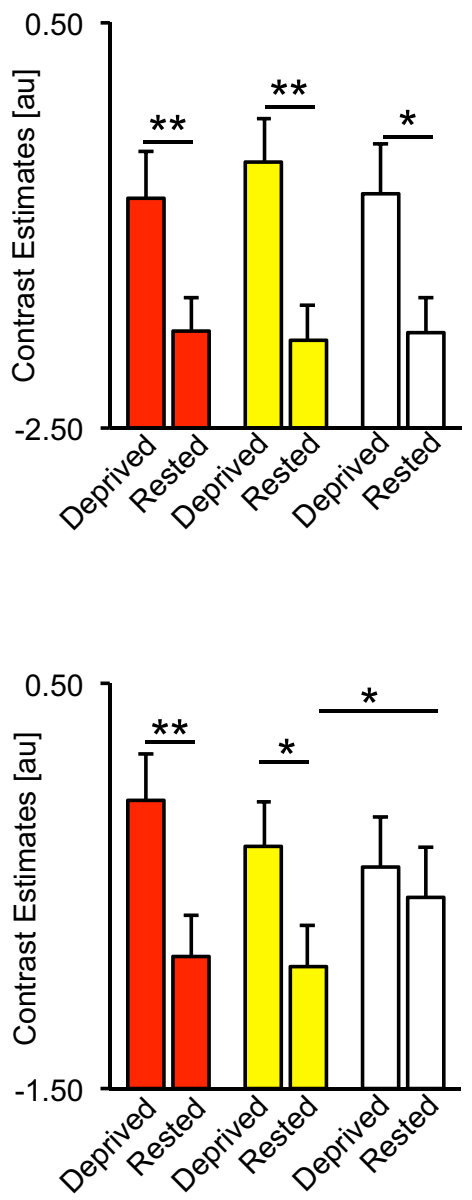

Figure 2. A, Brain maps displaying ROI mask (left brain image) and the ANOVA main effect of condition (sleep deprivation, sleep rested; right brain image) from the voxelwise ROI analysis in bilateral amygdala across all three cue types (negative, neutral, and ambiguous) [peak MNI coordinates $(x, y, z)$; left: $-18,-6,-16$; right: $24,-2,-16]$. Right side bar graphs illustrate the difference in average parameter estimates across the $6 \mathrm{~mm}$ ROI spheres between the sleep-deprivation and sleep-rested conditions, and average signal for each condition, respectively. $\boldsymbol{B}$, Brain maps displaying ROI mask (left brain image) and the ANOVA condition- cue type (negative, neutral, and ambiguous) interaction results from the voxelwise ROl analysis in the right anterior insula for the three cue types [peak MNI coordinates $(x, y, z) ; 32,20,14$ ], together with equivalent bar graphs as in $A$. No significant main effect of condition or cue type interaction was observed in the left anterior insula at FWE $p<0.05$. Error bars represent SEM. Within-region statistics: ${ }^{*} p<0.05$, ${ }^{* *} p<0.01$.

whole-brain voxelwise analysis (Table 5). In contrast to the right anterior insula, amygdala responses demonstrated no significant relationship with STAI trait scores using either the voxelwise or average ROI analysis, as was also the case for the left anterior insula (all $R<0.35, p>0.17$ ). Exploratory analyses assessing the laterality of the right insula association with the STAI revealed a significant asymmetry when using either the a priori left insula ROI or the aforementioned left insula region in the homologous location as the a priori right insula ROI (both $Z>2.28, p<0.01$ ). To test the specificity of this effect for the STAI trait anxiety scale, we examined associations with other self-report measures. No significant predictive associations were identified between the change in anterior insula or amygdala reactivity and any other assessed trait measure of affect (all $R<0.26, p>0.30$ ) or state measures of affect and sleepiness (all $R<0.40, p>0.12$ ).

Impact of sleep deprivation on subjective sleepiness, state anxiety, and behavior

Subjective sleepiness scores on the SSS showed the expected increase following sleep deprivation (Table 1). A repeatedmeasures condition (sleep-rested, sleep-deprived)-time-of-day (evening, morning) ANOVA revealed a main effect of condition
$(F=24.78, p=0.0001)$ and a condition-time-of-day interaction $(F=28.22, p=0.0001)$. Post hoc analyses demonstrated that sleep deprivation significantly increased subjective sleepiness across the night ( $T=5.37, p=0.0001)$, whereas sleep reduced subjective sleepiness across the rested night $(T=3.35, p=0.002)$. These findings support the likelihood that participants were subjectively rested and alert at the time of the sleep-rested test session, and that the manipulation of sleep deprivation was effective.

An analogous ANOVA was performed for STAI state scores, revealing effects of condition $(F=12: 00, p=0.0028)$, time of day $(F=24.64, p=0.0001)$, and condition-time of day $(F=14.09$, $p=0.0019)$ (Table 1). Post hoc analyses demonstrated that sleep deprivation elevated STAI state levels $(T=4.83, p=$ 0.002 ), while sleep nonsignificantly increased STAI state scores $(T=1.99, p=0.06)$.

Corresponding to the higher subjective sleepiness ratings on the SSS in the sleep-deprived condition, there were more omitted trials on the fMRI task in the sleep-deprived relative to the sleeprested condition $(T=3.24, p<0.01)$, consistent with previous deprivation studies (Van Dongen et al., 2003). Conversely, task trial response times were not significantly different between the two conditions ( $T=1.14, p=0.27)$. Of note, omitted trials in 
Table 3. Voxelwise whole-brain results for the ANOVA main effect of condition

\begin{tabular}{|c|c|c|c|c|c|}
\hline Region (Brodmann's area) & $\begin{array}{l}\text { Cluster } \\
\text { size }\left(\mathrm{mm}^{3}\right)\end{array}$ & $x$ & $y$ & $z$ & $\begin{array}{l}\text { Peak } \\
\text { Z score }\end{array}$ \\
\hline Anterior insula (13), right & 350 & 32 & 22 & 14 & 3.58 \\
\hline Posterior insula (13), left & 569 & -48 & -40 & 22 & 3.52 \\
\hline Parahippocampal gyrus (34), right & 4725 & 24 & 6 & -22 & 3.8 \\
\hline Amygdala, right & 2134 & 24 & -2 & -16 & 3.76 \\
\hline Amygdala, left & 2931 & -18 & -6 & -16 & 4.24 \\
\hline Fusiform gyrus (37), left & 28656 & -28 & -42 & -16 & 5.4 \\
\hline Fusiform gyrus (37), right & 67441 & 28 & -50 & -14 & 5.38 \\
\hline Precentral gyrus (6), left & 35000 & -42 & -8 & 54 & 5.1 \\
\hline Precentral gyrus (6), right & 197 & 52 & -14 & 30 & 3.28 \\
\hline Superior temporal gyrus (22), left & 14853 & -60 & -6 & -2 & 4.8 \\
\hline Superior temporal gyrus (22), right & 1225 & 56 & -34 & 16 & 3.78 \\
\hline Claustrum, left & 2494 & -34 & -10 & 12 & 4.57 \\
\hline Claustrum, right & 2450 & 32 & -8 & 14 & 3.78 \\
\hline Middle temporal gyrus (39), left & 31500 & -46 & -68 & 12 & 4.5 \\
\hline Inferior frontal gyrus (9), right & 5425 & 46 & 4 & 28 & 4.42 \\
\hline Hippocampus, right & 656 & 28 & -18 & -16 & 3.72 \\
\hline Postcentral gyrus (43), right & 7569 & 68 & -10 & 18 & 4.12 \\
\hline Postcentral gyrus (43), left & 1116 & -36 & -36 & 50 & 3.4 \\
\hline Middle cingulate gyrus (24), left & 2100 & -2 & -2 & 50 & 3.69 \\
\hline Middle cingulate gyrus (24), right & 284 & 10 & 4 & 34 & 3.68 \\
\hline Inferior parietal lobule (7), left & 175 & -44 & -72 & 46 & 3.42 \\
\hline Caudate body, left & 44 & -16 & 6 & 18 & 3.21 \\
\hline Subgyral (20), right & 66 & 46 & -16 & -22 & 3.21 \\
\hline Precuneus (7), left & 22 & -20 & -58 & 60 & 3.21 \\
\hline Putamen, right & 66 & 32 & -18 & 12 & 3.14 \\
\hline
\end{tabular}

Uncorrected $p<0.001,>10 \mathrm{~mm}^{3}$ contiguous cluster extent.

Table 4. Voxelwise whole-brain results for the ANOVA condition-cue type interaction

\begin{tabular}{lcrrrr}
\hline Region (Brodmann's area) & Cluster size $\left(\mathrm{mm}^{3}\right)$ & $x$ & $y$ & $z$ & PeakZscore \\
\hline Anterior insula (13), right & 197 & 32 & 20 & 14 & 3.55 \\
Cerebellar tonsil, left & 2209 & -8 & -34 & -44 & 3.79 \\
Cerebellar tonsil, right & 547 & 16 & -38 & -46 & 3.27 \\
Inferior parietal lobule (40), right & 788 & 42 & -58 & 38 & 3.6 \\
Medial frontal gyrus (8), left & 44 & -10 & 38 & 42 & 3.24 \\
Middle frontal gyrus (47), left & 22 & -54 & 46 & -10 & 3.18 \\
\hline
\end{tabular}

Uncorrected $p<0.001,>10 \mathrm{~mm}^{3}$ contiguous cluster extent.

both conditions were modeled separately and not included in the anticipation fMRI contrast.

\section{Discussion}

Together, our findings demonstrate that sleep deprivation amplifies preemptive amygdala and anterior insula responding during the anticipation of potentially aversive experiences. Additionally, these results help determine the anatomical and contextual specificity under which this neural increase does and does not occur. Finally, our data further establish that trait anxiety confers significant vulnerability to these increased anticipatory neural responses following sleep loss.

Enhanced affective anticipatory sensitivity following sleep deprivation was observed in both our target regions of interest: the amygdala and anterior insula (see Table 3 for alterations beyond these ROIs). However, this change was uniquely different for each region on the basis of the different anticipatory cues. Within the amygdala, the enhanced anticipatory response was common across cue types, independent of valence or certainty. This anticipatory change differs from the already characterized alteration in amygdala reactivity to emotional stimuli themselves, which showed selective increases only to emotional rather than nonemotional stimuli (Yoo et al., 2007; Gujar et al., 2011). Therefore,

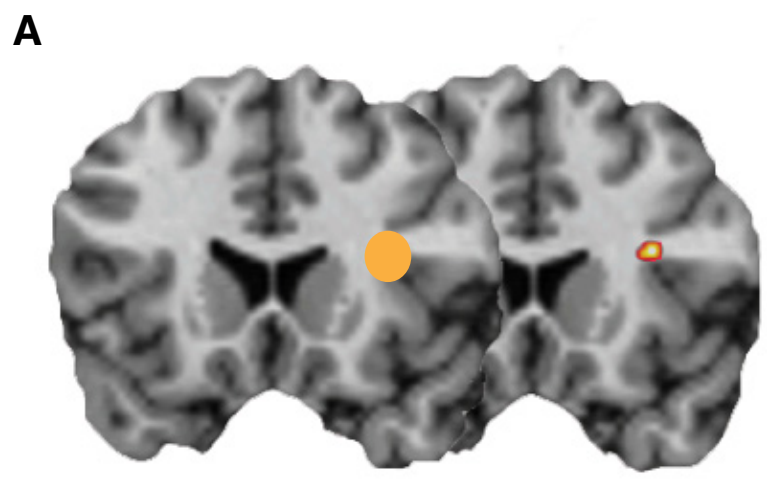

B

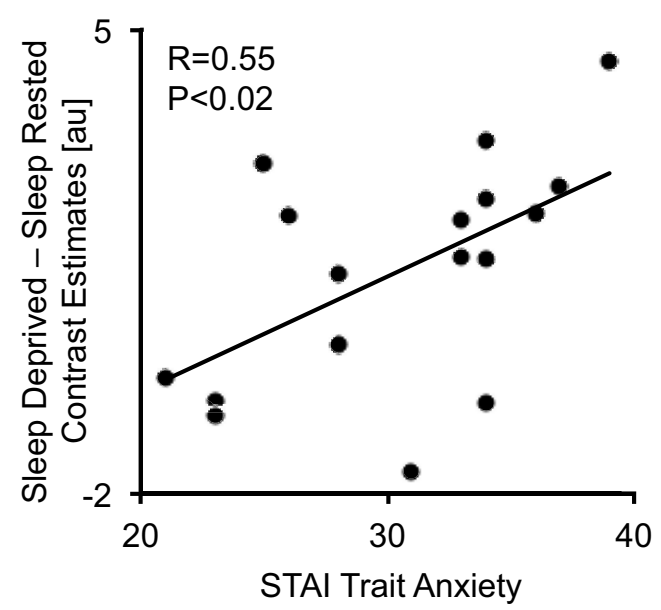

Figure 3. $\quad \boldsymbol{A}$, Brain maps displaying anterior insula ROI mask (left brain image) and the voxelwise $\mathrm{ROI}$ regression between STAI trait anxiety and the relative sleep deprivation induced increase in anticipatory response in anterior insula for all cues [peak MNI coordinates $(x, y, z) ; 34$, $18,18 ; T=4.04, p<0.001]$. Regression thresholded at $p<0.05$ FWE-corrected for multiple comparisons. $\boldsymbol{B}$, Scatterplot displaying this same relationship using the average parameter estimates across the $6 \mathrm{~mm}$ ROI anterior insula ROI mask (left brain image).

Table 5. Voxelwise whole-brain regression between STAI-trait anxiety and the condition difference in anticipation reactivity

\begin{tabular}{lrrrrl}
\hline Region (Brodmann's area) & Cluster size $\left(\mathrm{mm}^{3}\right)$ & $x$ & $y$ & $z$ & Peak Zscore \\
\hline Anterior insula (13), right & 22 & 34 & 18 & 18 & 3.27 \\
Posterior cingulate gyrus (31), left & 1050 & -26 & -58 & 26 & 3.91 \\
Cuneus (30), left & 284 & -26 & -74 & 12 & 3.67 \\
Inferior parietal lobule (39), left & 109 & -48 & -72 & 42 & 3.54 \\
Claustrum, right & 88 & 28 & 12 & 20 & 3.48 \\
Middle frontal gyrus (9), right & 241 & 28 & 18 & 32 & 3.43 \\
Middle frontal gyrus (9), left & 22 & -48 & 42 & 28 & 3.37 \\
Precentral gyrus (4), right & 66 & 28 & -18 & 50 & 3.4 \\
Inferior temporal gyrus (20), right & 44 & 54 & -24 & -22 & 3.31 \\
Postcentral gyrus (1), right & 109 & 60 & -18 & 52 & 3.27 \\
\hline
\end{tabular}

SD $>$ SR, all cues; uncorrected $p<0.001,>10 \mathrm{~mm}^{3}$ contiguous cluster extent. SD, sleep deprived; SR, sleep rested.

sleep loss resulted in a profile of generalized anticipatory signaling within the amygdala, potentially reflecting a preparatory brain state of heightened threat expectancy (Adolphs, 2010; Thayer et al., 2012). While this may be adaptive to the organism in the compromised and fatigued condition of sleep deprivation, similar profiles of excessive amygdala reactivity (independent of sleep status) have been reported in psychopathology, and occur at the cost of optimal judgment and decision-making, indicative of maladaptive consequences (Hoehn-Saric et al., 
2004; Nitschke et al., 2009; Etkin et al., 2010; Pessoa, 2010). Indeed, sleep deprivation impairs behavioral task performance on affective decision tests known to involve amygdala function, consistent with this latter maladaptive hypothesis (Killgore et al., 2006, 2007a,b; Anderson and Dickinson, 2010; Anderson and Platten, 2011).

Unlike the amygdala, the right anterior insula demonstrated hyperactivity following sleep deprivation only in a specific anticipatory context: that of cues predicting outcome certainty regardless of valence. Under sleep-rested conditions, the anterior insula demonstrated greater anticipatory signaling of impending uncertainty, consistent with previous reports highlighting a role for the anterior insula in uncertainty processing (Huettel et al., 2005; Dunsmoor et al., 2007; Herwig et al., 2007; Preuschoff et al., 2008; Somerville et al., 2013). This specificity has been considered advantageous, providing a qualitative prediction of impending threat that allows for adaptive decision-making, especially when future events are unpredictable (Loewenstein et al., 2001; Singer et al., 2009). Conversely, generalized rather than specific anterior insula responding both to certain as well as uncertain cues has been proposed to account for the dysfunctional affective state of anxiety, resulting in heightened subjective estimates about impending future outcomes, thereby treating all predictive cues as threatening (Simmons et al., 2006, 2008, 2011; Nitschke et al., 2009). Similar to this latter profile, and in contrast to the selective anterior insula anticipatory signaling of uncertainty following a full night of sleep, participants showed an inverted insula pattern of responding when sleep deprived, driven by elevated responses to both types of certain cues. Such disrupted signaling within the anterior insula may prevent the discrimination of, and hence appropriate preparation for, events of varied affective probability under conditions of sleep loss. It may further result in the sleep-deprived brain treating all cues as potentially aversive; a bias that has similarly been reported in anxiety disorders (Hoehn-Saric et al., 2004; Nitschke et al., 2009) and is congruent with the subjective anxiogenic consequence of sleep deprivation (Babson et al., 2009, 2010). Although observed for the right but not left anterior insula, these effects were not statistically asymmetric.

Trait anxiety levels predicted susceptibility to the amplifying impact of sleep deprivation within the anterior insula. Therefore, those individuals with elevated trait anxiety - who, parenthetically, are those already at higher risk for developing an anxiety or mood disorder-demonstrated the greatest vulnerability to the impact of sleep loss within the insula. The association with trait anxiety was specific to the right anterior insula, and was not observed in either the left anterior insula or amygdala. This statistically significant insula asymmetry contributes to an ongoing discussion in the literature about anatomic specificity and laterality in insula function (Damasio, 2003; Craig, 2009; Deen et al., 2011; Simmons et al., 2011). The absence of trait anxiety relationships with increased amygdala anticipatory activity within the current study in no way challenges established associations between anxiety and amygdala function (Birbaumer et al., 1998; Thomas et al., 2001; Etkin and Wager, 2007; Davis et al., 2010; Somerville et al., 2013). Instead, these finding simply indicate that the change in amygdala reactivity induced by sleep deprivation, relative to the sleep-rested condition, appears to robustly occur independent of trait anxiety levels.

This right insula association with trait anxiety is of potential clinical relevance given that excessive anticipatory insula activity is a characteristic of most anxiety disorders (Simmons et al., 2006, 2011; Etkin and Wager, 2007) and, further, that sleep disruption is a recognized symptom of anxiety disorders (Harvey et al., 2011). Together with previous reports describing behavioral associations between anxiety and sleep loss (Sagaspe et al., 2006), such data support an emerging neuropathological model in which sleep disruption may not only be a symptom of anxiety, but potentially contributes to the maintenance and/or exacerbation of rumination and worry through hyperlimbic anticipatory reactions. Moreover, the data raise the therapeutic possibility that targeted sleep restoration may beneficially ameliorate such neural and psychological symptomatology both in anxiety disorders and subclinical high-anxious individuals.

Finally, our findings should be appreciated within the context of certain limitations. First, the range of STAI trait scores across our participants was relatively narrow, which affects the generalizability of the association observed with the anterior insula. Whether similar relationships would be observed in samples with a larger range, and in those with clinically diagnosed anxiety, is not known. Second is the lack of a polysomnographic screening night to verify the absence of sleep disorders characterized using validated screening questionnaires (Horne and Ostberg, 1976; Buysse et al., 1989). A related issue in the current study is the lack of an adaptation night in the sleep laboratory, which may have resulted in poorer sleep quality during the sleep-rested night (Agnew et al., 1966; Kingshott and Douglas, 2000). This is an issue that, if present, may suggest that the effects we observed would be stronger when participants are in a fully sleep-rested state. However, three aspects of empirical data suggest that our participants were likely well rested on the morning of the sleep-rested session: (1) participants reported a high degree of functioning and concentration on a validated measure of alertness (Hoddes et al., 1973 ) on the evening before the experimental manipulation and on the morning of the sleep-rested test session; (2) the sleeprested night resulted in significantly increased subjective alertness scores the next morning (while the sleep-deprivation condition resulted in significantly decreased alertness scores when assessed at the equivalent times); and (3) the duration and sleep-stage amounts measured on the rested night conform well to age and population norms (Ohayon et al., 2004).

In summary, here we demonstrate that sleep loss exaggerates preemptive responding in the amygdala and anterior insula during affective anticipation. Furthermore, trait anxiety confers significant neural vulnerability to these amplifying effects of sleep loss in the anterior insula, a finding that may hold translational implications regarding the co-occurrence between sleep disruption and anxiety disorders.

\section{References}

Adolphs R (2010) What does the amygdala contribute to social cognition? Ann N Y Acad Sci 1191:42-61. CrossRef Medline

Agnew HW Jr, Webb WB, Williams RL (1966) The first night effect: an EEG study of sleep. Psychophysiology 2:263-266. CrossRef Medline

Anderson C, Dickinson DL (2010) Bargaining and trust: the effects of 36-h total sleep deprivation on socially interactive decisions. J Sleep Res 19:5463. CrossRef Medline

Anderson C, Platten CR (2011) Sleep deprivation lowers inhibition and enhances impulsivity to negative stimuli. Behav Brain Res 217:463-466. CrossRef Medline

Babson KA, Feldner MT, Trainor CD, Smith RC (2009) An experimental investigation of the effects of acute sleep deprivation on panic-relevant biological challenge responding. Behav Ther 40:239-250. CrossRef Medline

Babson KA, Trainor CD, Feldner MT, Blumenthal H (2010) A test of the effects of acute sleep deprivation on general and specific self-reported anxiety and depressive symptoms: an experimental extension. J Behav Ther Exp Psychiatry 41:297-303. CrossRef Medline 
Birbaumer N, Grodd W, Diedrich O, Klose U, Erb M, Lotze M, Schneider F, Weiss U, Flor H (1998) fMRI reveals amygdala activation to human faces in social phobics. Neuroreport 9:1223-1226. CrossRef Medline

Buysse DJ, Reynolds CF 3rd, Monk TH, Berman SR, Kupfer DJ (1989) The Pittsburgh Sleep Quality Index: a new instrument for psychiatric practice and research. Psychiatry Res 28:193-213. CrossRef Medline

Costa PT Jr, McCrae RR (1997) Stability and change in personality assessment: the revised NEO Personality Inventory in the year 2000. J Pers Assess 68:86-94. CrossRef Medline

Craig AD (2009) How do you feel-now? The anterior insula and human awareness. Nat Rev Neurosci 10:59-70. CrossRef Medline

Dale AM (1999) Optimal experimental design for event-related fMRI. Hum Brain Mapp 8:109-114. Medline

Damasio AR (2003) Looking for Spinoza: joy, sorrow, and the feeling brain. Orlando, FL: Harcourt.

Davis M, Walker DL, Miles L, Grillon C (2010) Phasic vs sustained fear in rats and humans: role of the extended amygdala in fear vs anxiety. Neuropsychopharmacology 35:105-135. CrossRef Medline

Deen B, Pitskel NB, Pelphrey KA (2011) Three systems of insular functional connectivity identified with cluster analysis. Cereb Cortex 21: 1498-1506. CrossRef Medline

Dunsmoor JE, Bandettini PA, Knight DC (2007) Impact of continuous versus intermittent CS-UCS pairing on human brain activation during Pavlovian fear conditioning. Behav Neurosci 121:635-642. CrossRef Medline

Etkin A, Wager TD (2007) Functional neuroimaging of anxiety: a metaanalysis of emotional processing in PTSD, social anxiety disorder, and specific phobia. Am J Psychiatry 164:1476-1488. CrossRef Medline

Etkin A, Prater KE, Hoeft F, Menon V, Schatzberg AF (2010) Failure of anterior cingulate activation and connectivity with the amygdala during implicit regulation of emotional processing in generalized anxiety disorder. Am J Psychiatry 167:545-554. CrossRef Medline

Freeston M, Rheaume J, Letarte H, Dugas M, Ladouceur R (1994) Why do people worry? Pers Indiv Diff 17:792-802.

Friston KJ, Holmes AP, Worsley KJ, Poline J-P, Frith CD, Frackowiak RSJ (1994) Statistical parametric maps in functional imaging: a general linear approach. Hum Brain Mapp 2:189-210. CrossRef

Friston KJ, Glaser DE, Henson RN, Kiebel S, Phillips C, Ashburner J (2002) Classical and Bayesian inference in neuroimaging: applications. Neuroimage 16:484-512. CrossRef Medline

Grupe DW, Oathes DJ, Nitschke JB (2012) Dissecting the anticipation of aversion reveals dissociable neural networks. Cereb Cortex. Advance online publication. Retrieved February 24, 2013. doi:10.1093/cercor/ bhs175. CrossRef Medline

Gujar N, McDonald SA, Nishida M, Walker MP (2011) A role for REM sleep in recalibrating the sensitivity of the human brain to specific emotions. Cereb Cortex 21:115-123. CrossRef Medline

Harvey AG, Murray G, Chandler RA, Soehner A (2011) Sleep disturbance as transdiagnostic: consideration of neurobiological mechanisms. Clin Psychol Rev 31:225-235. CrossRef Medline

Herwig U, Kaffenberger T, Baumgartner T, Jäncke L (2007) Neural correlates of a 'pessimistic' attitude when anticipating events of unknown emotional valence. Neuroimage 34:848-858. CrossRef Medline

Hoddes E, Zarcone V, Smythe H, Phillips R, Dement WC (1973) Quantification of sleepiness: a new approach. Psychophysiology 10:431-436. CrossRef Medline

Hoehn-Saric R, Schlund MW, Wong SH (2004) Effects of citalopram on worry and brain activation in patients with generalized anxiety disorder. Psychiatry Res 131:11-21. CrossRef Medline

Horne JA, Ostberg O (1976) A self-assessment questionnaire to determine morningness-eveningness in human circadian rhythms. Int J Chronobiol 4:97-110. Medline

Huettel SA, Song AW, McCarthy G (2005) Decisions under uncertainty: probabilistic context influences activation of prefrontal and parietal cortices. J Neurosci 25:3304-3311. CrossRef Medline

Kesner RP, Gilbert PE (2007) The role of the agranular insular cortex in anticipation of reward contrast. Neurobiol Learn Mem 88:82-86. CrossRef Medline

Killgore WD, Balkin TJ, Wesensten NJ (2006) Impaired decision making following $49 \mathrm{~h}$ of sleep deprivation. J Sleep Res 15:7-13. CrossRef Medline

Killgore WD, Killgore DB, Day LM, Li C, Kamimori GH, Balkin TJ (2007a) The effects of 53 hours of sleep deprivation on moral judgment. Sleep 30:345-352. Medline
Killgore WD, Lipizzi EL, Kamimori GH, Balkin TJ (2007b) Caffeine effects on risky decision making after 75 hours of sleep deprivation. Aviat Space Environ Med 78:957-962. CrossRef Medline

Kingshott RN, Douglas NJ (2000) The effect of in-laboratory polysomnography on sleep and objective daytime sleepiness. Sleep 23:1109-1113. Medline

Kriegeskorte N, Simmons WK, Bellgowan PS, Baker CI (2009) Circular analysis in systems neuroscience: the dangers of double dipping. Nat Neurosci 12:535-540. CrossRef Medline

Lang PJ, Bradley MM, Cuthbert BN (1997) International Affective Picture System (IAPS): technical manual and affective ratings. Gainesville, FL: University of Florida.

Loewenstein GF, Weber EU, Hsee CK, Welch N (2001) Risk as feelings. Psychol Bull 127:267-286. CrossRef Medline

Mackiewicz KL, Sarinopoulos I, Cleven KL, Nitschke JB (2006) The effect of anticipation and the specificity of sex differences for amygdala and hippocampus function in emotional memory. Proc Natl Acad Sci U S A 103: 14200-14205. CrossRef Medline

Masaoka Y, Hirasawa K, Yamane F, Hori T, Homma I (2003) Effects of left amygdala lesions on respiration, skin conductance, heart rate, anxiety, and activity of the right amygdala during anticipation of negative stimulus. Behav Modif 27:607-619. CrossRef Medline

McNally GP, Westbrook RF (2006) Predicting danger: the nature, consequences, and neural mechanisms of predictive fear learning. Learn Mem 13:245-253. CrossRef Medline

Nitschke JB, Sarinopoulos I, Mackiewicz KL, Schaefer HS, Davidson RJ (2006) Functional neuroanatomy of aversion and its anticipation. Neuroimage 29:106-116. CrossRef Medline

Nitschke JB, Sarinopoulos I, Oathes DJ, Johnstone T, Whalen PJ, Davidson RJ, Kalin NH (2009) Anticipatory activation in the amygdala and anterior cingulate in generalized anxiety disorder and prediction of treatment response. Am J Psychiatry 166:302-310. CrossRef Medline

Nitschke J, Heller W, Imig J, McDonald R, Miller G (2001) Distinguishing dimensions of anxiety and depression. Cogn Ther Res 25:1-22. CrossRef

Ohayon MM, Carskadon MA, Guilleminault C, Vitiello MV (2004) Metaanalysis of quantitative sleep parameters from childhood to old age in healthy individuals: developing normative sleep values across the human lifespan. Sleep 27:1255-1273. Medline

Pessoa L (2010) Emotion and cognition and the amygdala: from "what is it?" to "what's to be done?" Neuropsychologia 48:3416-3429. CrossRef Medline

Poldrack RA (2007) Region of interest analysis for fMRI. Soc Cogn Affect Neurosci 2:67-70. Medline

Poldrack RA, Mumford JA (2009) Independence in ROI analysis: where is the voodoo? Soc Cogn Affect Neurosci 4:208-213. CrossRef Medline

Preuschoff K, Quartz SR, Bossaerts P (2008) Human insula activation reflects risk prediction errors as well as risk. J Neurosci 28:2745-2752. CrossRef Medline

Rush AJ, Trivedi MH, Ibrahim HM, Carmody TJ, Arnow B, Klein DN, Markowitz JC, Ninan PT, Kornstein S, Manber R, Thase ME, Kocsis JH, Keller MB (2003) The 16-Item Quick Inventory of Depressive Symptomatology (QIDS), clinician rating (QIDS-C), and self-report (QIDS$\mathrm{SR})$ : a psychometric evaluation in patients with chronic major depression. Biol Psychiatry 54:573-583. CrossRef Medline

Sagaspe P, Sanchez-Ortuno M, Charles A, Taillard J, Valtat C, Bioulac B, Philip P (2006) Effects of sleep deprivation on Color-Word, Emotional, and Specific Stroop interference and on self-reported anxiety. Brain Cogn 60:76-87. CrossRef Medline

Sarinopoulos I, Grupe DW, Mackiewicz KL, Herrington JD, Lor M, Steege EE, Nitschke JB (2010) Uncertainty during anticipation modulates neural responses to aversion in human insula and amygdala. Cereb Cortex 20:929-940. CrossRef Medline

Simmons AN, Paulus MP, Thorp SR, Matthews SC, Norman SB, Stein MB (2008) Functional activation and neural networks in women with posttraumatic stress disorder related to intimate partner violence. Biol Psychiatry 64:681-690. CrossRef Medline

Simmons AN, Stein MB, Strigo IA, Arce E, Hitchcock C, Paulus MP (2011) Anxiety positive subjects show altered processing in the anterior insula during anticipation of negative stimuli. Hum Brain Mapp 32:1836-1846. CrossRef Medline

Simmons A, Matthews SC, Stein MB, Paulus MP (2004) Anticipation of 
emotionally aversive visual stimuli activates right insula. Neuroreport 15:2261-2265. CrossRef Medline

Simmons A, Strigo I, Matthews SC, Paulus MP, Stein MB (2006) Anticipation of aversive visual stimuli is associated with increased insula activation in anxiety-prone subjects. Biol Psychiatry 60:402-409. CrossRef Medline

Singer T, Critchley HD, Preuschoff K (2009) A common role of insula in feelings, empathy and uncertainty. Trends Cogn Sci 13:334-340. CrossRef Medline

Somerville LH, Wagner DD, Wig GS, Moran JM, Whalen PJ, Kelley WM (2013) Interactions between transient and sustained neural signals support the generation and regulation of anxious emotion. Cereb Cortex 23:49-60. CrossRef Medline

Spielbeger CD (1983) Spielberger State Trait Anxiety Inventory. Palo Alto, CA: Consulting Psychologists.

Thayer JF, Ahs F, Fredrikson M, Sollers JJ 3rd, Wager TD (2012) A metaanalysis of heart rate variability and neuroimaging studies: implications for heart rate variability as a marker of stress and health. Neurosci Biobehav Rev 36:747-756. CrossRef Medline

Thomas KM, Drevets WC, Dahl RE, Ryan ND, Birmaher B, Eccard CH, Axelson D, Whalen PJ, Casey BJ (2001) Amygdala response to fearful faces in anx- ious and depressed children. Arch Gen Psychiatry 58:1057-1063. CrossRef Medline

van der Helm E, Yao J, Dutt S, Rao V, Saletin JM, Walker MP (2011) REM sleep depotentiates amygdala activity to previous emotional experiences. Curr Biol 21:2029-2032. CrossRef Medline

Van Dongen HP, Maislin G, Mullington JM, Dinges DF (2003) The cumulative cost of additional wakefulness: dose-response effects on neurobehavioral functions and sleep physiology from chronic sleep restriction and total sleep deprivation. Sleep 26:117-126. Medline

Vul E, Harris C, Winkielman P, Pashler H (2009) Puzzlingly high correlations in fMRI studies of emotion, personality, and social cognition. Perspect Psychol Sci 4:274-290. CrossRef

Watson D, Weber K, Assenheimer JS, Clark LA, Strauss ME, McCormick RA (1995) Testing a tripartite model: I. Evaluating the convergent and discriminant validity of anxiety and depression symptom scales. J Abnorm Psychol 104:3-14. CrossRef Medline

Yoo SS, Gujar N, Hu P, Jolesz FA, Walker MP (2007) The human emotional brain without sleep—a prefrontal amygdala disconnect. Curr Biol 17: R877-R878. CrossRef Medline 